\section{'Kader' Peach: A Processing Clingstone Peach with Improved Harvest Quality and Disease Resistance, Ripening in the 'Dixon' Maturity Season}

\section{Thomas Gradziel ${ }^{\mathbf{1}}$ and Sabrina Marchand \\ Department of Plant Sciences, One Shields Avenue, University of California, Davis, CA 95616}

Additional index words. breeding, fruit, genetic-improvement, fruit brown-rot disease, uniform-harvest

'Kader' peach [Prunus persica (L.) Batsch] produces a clingstone, nonmelting fruit suitable for processing or fresh market. Evaluated as selection ' $90,9-116$ ', it was derived from a cross between breeding selection 'R1-1' and the University of California, Davis, cultivar Ross, which had 'Dixon', 'Elberta', and PI 292557 in its lineage. Ripening time occurs during the commercially important 'Dixon' period, $\approx 6 \mathrm{~d}$ before that of 'Fay Elberta'. During long-term commercial evaluations, fruit demonstrated very good harvest, postharvest, and processing quality, with low proportions of the undesirable endocarp or pit splitting and the associated red anthocyanin staining of fruit flesh, as occurs in many cultivars of this maturity. Fruit possess good firmness and color very similar to that of the commercially important cultivar Andross. Trees have proven to be consistently productive during more than 12 years of continuous commercial evaluation in environments with
$700 \mathrm{~h}$ or more of winter chilling. Tree form is semi-upright, with vigor and branch architecture similar to 'Andross'. Flowers are pink, showy, and large. Leaves are medium-to-dark green, with globose leaf glands.

\section{Origin}

The University of California at Davis (UCD) has maintained a processing peach breeding program since the 1980 s with the support of the California cling peach growers and processors. The primary objective of the breeding program was to develop replacements for the early maturity season cultivars Dixon and Andross. 'Dixon' was introduced in 1956, and it was one of the first extra-early maturity season cultivars that could consistently achieve commercially profitable yields when thinned to achieve desired fruit sizes of $60 \mathrm{~mm}$ or larger. Fruit flesh is a desirable yellow-gold and it possesses good fresh and processed eating quality, but the fruit pit cavity often develops a pink to red color from the formation of red anthocyanins. The anthocyanins oxidize to brown when heatprocessed, staining both the processed fruit and syrup. The 'Dixon' fruit endocarp or stone is also more susceptible to breakage, resulting in undesirable pit fragments in processed fruit. Because of these problems, processors discontinued 'Dixon' fruit purchases. Therefore, this cultivar is no longer
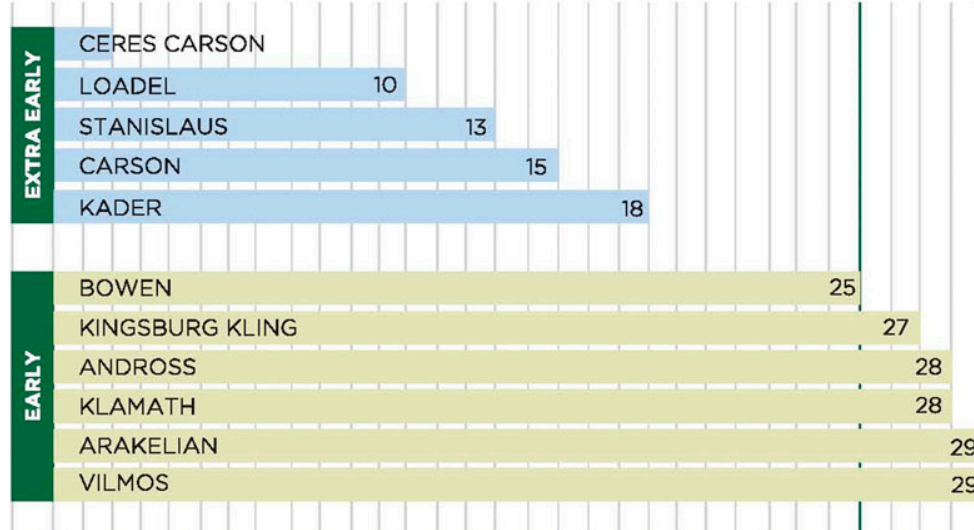

ROSS

DAVIS

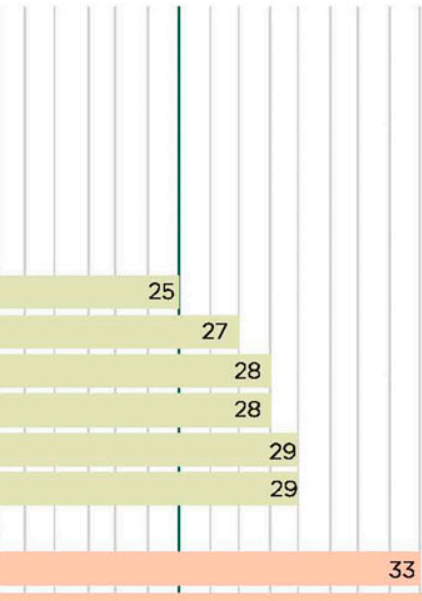

LILLELAND

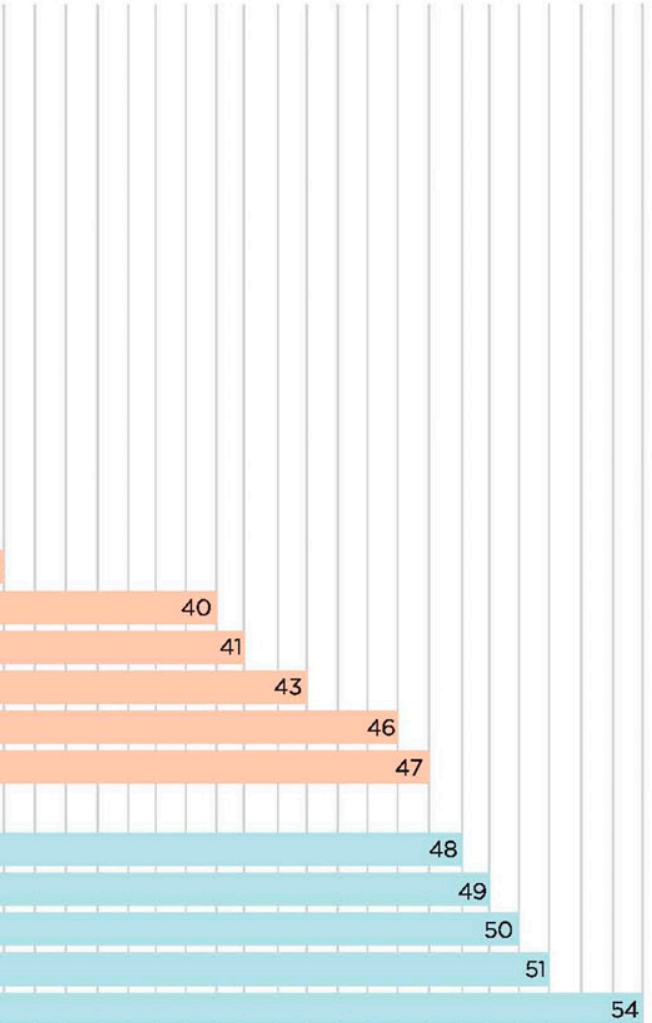

RIEGELS

STARN

HESSE

SULLIVAN \#4

CORONA

Fig. 1. Fruit maturity of 'Kader' relative to commercial canning clingstone peaches in California. In commercial production, the cultivar Dixon ripened $\approx 1$ week after 'Carson' and 1 week before 'Andross'. The production gap resulting from its removal from commercial planting is commonly known as the Dixon gap. 'Kingsburg-Cling' is an early ripening mutation of University of California at Davis cultivar Dr. Davis currently being test-planted as an alternative to cultivar Andross (California Canning Peach Association, 2017). 


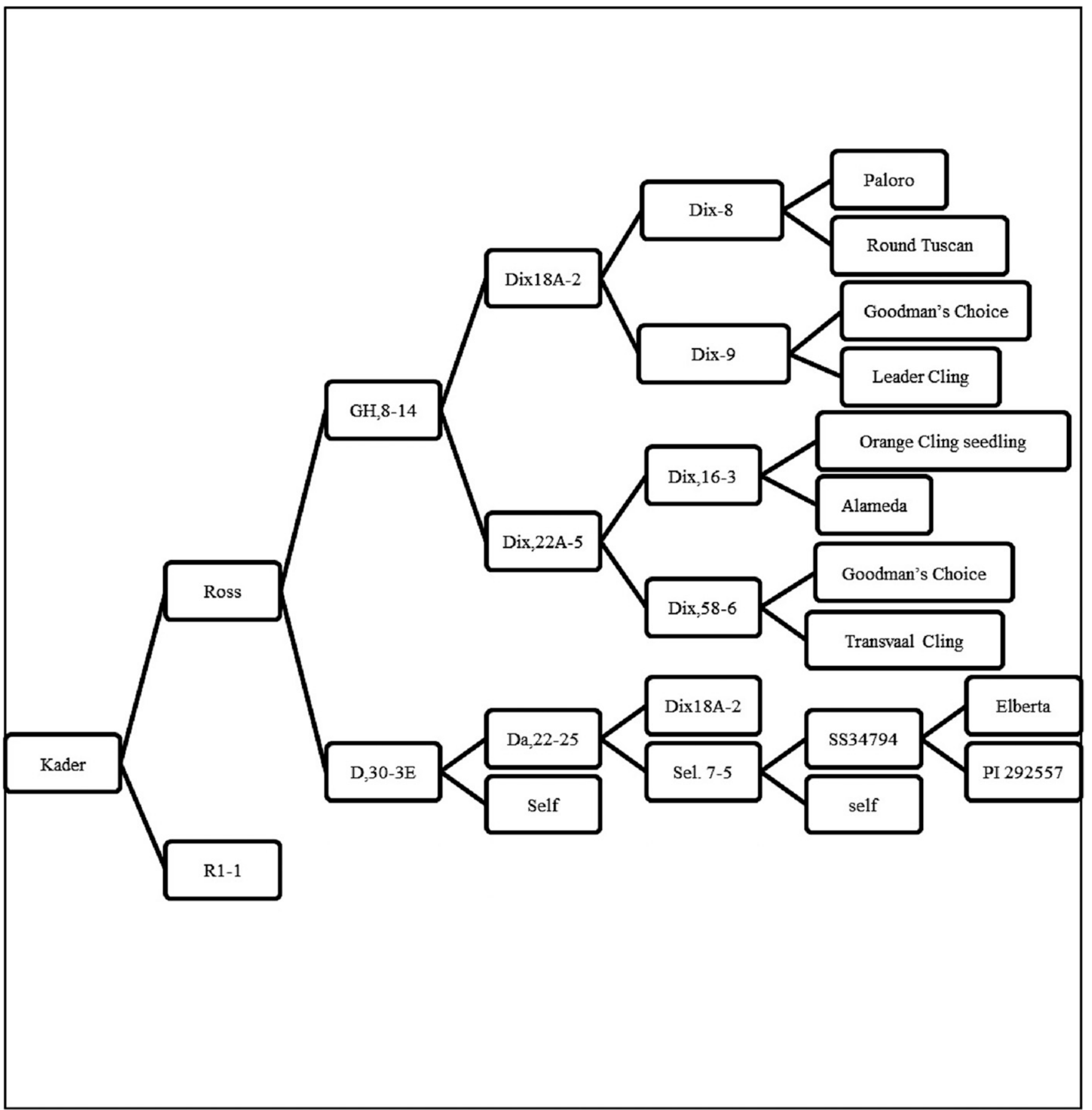

Fig. 2. Pedigree of the 'Kader' peach. Seed parent is presented at the top. The origin of the pollen parent R,1-1 is unknown. The designation PI 292557 is from early breeder records and does not refer to the ARS GRIN database.

commercially planted, and no replacement cultivar currently exists (Fig. 1). The cultivar Carson has remained the only commercially successful processing peach harvested during the resulting 'Dixon' gap, followed by the 'Andross' harvest season. 'Andross' was developed as a source of fruit for processors during the early maturity season following

Received for publication 31 Oct. 2018. Accepted for publication 5 Jan. 2019.

${ }^{1}$ Corresponding author. E-mail: tmgradziel@ ucdavis.edu.
'Dixon' production. 'Andross' originated from a cross with 'Dixon' as a grandparent and was introduced in 1964. 'Andross' has become the most heavily planted cultivar during the early maturity season because of its proven potential to produce abundant firm fruit with good commercial size. 'Bowen', the only remaining established cultivar ripening during this season (Fig. 1), also has 'Dixon' as a grandparent, but it has never achieved high plantings due to inferior fruit quality and yields. Pedigree analysis has documented the extensive use of 'Dixon' as well as a sibling selection designated 'Dixon
\#2' during cultivar development efforts before the 1980s (Gradziel et al., 1993). With the release of the UCD cultivars Dr. Davis and Ross in the 1980s, new, yet highly adapted germplasm derived from the germplasm identified in breeder records as 'PI292557' and the freestone cultivar Elberta were made available for continued genetic improvement. Because of their high fruit quality and yield potential, Dr. Davis and Ross have become the most extensively planted processing peach cultivars in California. 'Kader' is a product of a breeding effort to combine desirable traits of 'Andross' and 'Ross' during a controlled cross between 


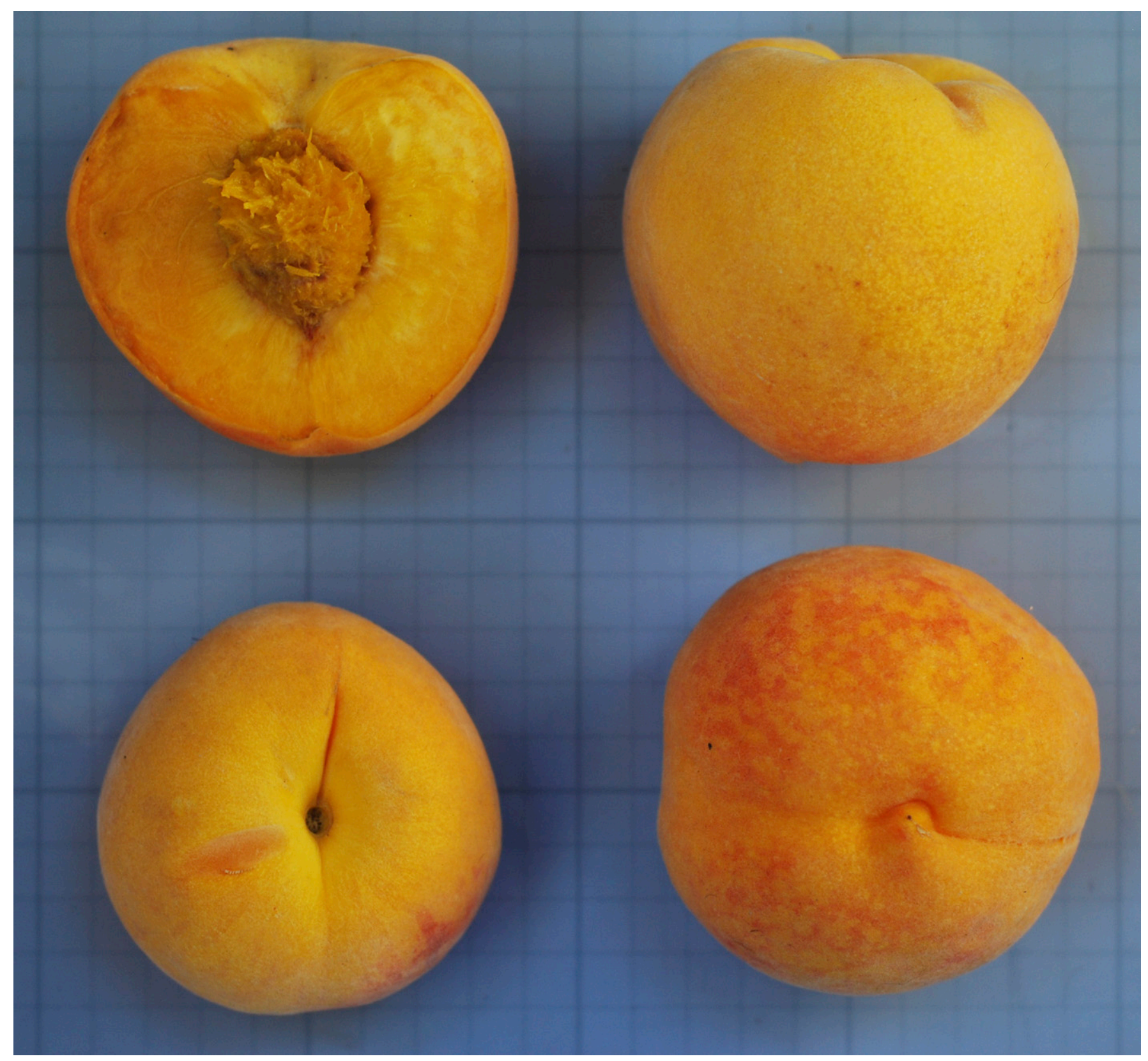

Fig. 3. Fruit and stone morphology of 'Kader' peach (grid $=1 \mathrm{~cm}$ ).

University of California processing peach breeding line ' $\mathrm{R}, 1-1$ ' as the male (pollen) parent and the University of California processing peach cultivar Ross as the female (seed) parent (Fig. 2). Originally designated as seedling ' $90,9-116$ ', it was selected based on its good fruit and tree qualities, its freedom from red staining of the pit, low frequency of pit fragments in processed flesh, and desirable ripening time that occurs $10 \mathrm{~d}$ before that of the cultivar Andross. Regional evaluation plots for '90,9-116' were established in 2001 at Winters, CA and Davis, CA in the Sacramento Valley and at the Kearney Agricultural Center in Parlier, CA in the San Joaquin Valley, and in 2004 at multiple grower evaluation plots in the Sacramento and San Joaquin Valleys under the designation 'UCDExtra-Early \#1'. Based on its positive evaluations, selection '90,9-116' has been patented and released as the processing peach cultivar Kader.
The name 'Kader' was chosen to acknowledge the extensive contributions to peach harvest and postharvest knowledge by Professor Adel Kader during his career in the Department of Pomology, and subsequently in the Department of Plant Sciences at UCD.

\section{Description}

'Kader' peach [Prunus persica (L.) Batsch] ripens during the commercially important 'Dixon' period, between the periods of 'Carson' and 'Andross'. In addition to its desirable ripening period, the processing clingstone fruit have a low incidence of undesirable pit-splitting and red anthocyanin staining of pit cavities, as occurs in the Dixon and Andross cultivars. Fruit are large, slightly ovate to round, and have a slight fruit tip, although they are free from the elongated tip found on several clingstone peach cultivars following mild winter and warm spring weather (Fig. 3). Flesh is bright yellow to yellow-gold, with improved resistance to fruit brown rot (Monilinia fructicola) in field and controlled laboratory conditions. Fruit skin is slightly less pubescent than that of 'Andross', with a more uniform golden-yellow color. Pit has a medium size and has remained free from the red staining and extensive pit fragmentation of 'Dixon' and 'Andross', even in environments promoting these conditions. Tree is semi-upright, with vigor similar to that of 'Andross'. Branch architecture is similar to that of 'Andross', although often with a denser canopy. Flowers are pink, showy, and large; two flowers per node are commonly present. Leaves are medium-to-dark green with globose leaf glands, similar to those of 'Andross'. 
Table 1. Performance of 'Kader' clingstone processing peach compared with the California cultivars Carson and Andross. Fruit were from the University of California at Davis Wolfskill Experimental Orchards in Winters, CA as part of the 3-year RosBreed peach genome project (Gasic et al., 2011).

\begin{tabular}{|c|c|c|c|}
\hline & Carson & Kader & Andross \\
\hline$\overline{\text { Raw fruit size }(\mathrm{g} \mathrm{FW})^{2}}$ & $219.5 \mathrm{a}$ & $332.7 \mathrm{~b}$ & $332.2 \mathrm{~b}$ \\
\hline Processed flesh color ' $a$ ' value & $5.0 \mathrm{a}$ & $7.0 \mathrm{~b}$ & $6.9 \mathrm{~b}$ \\
\hline Processed flesh color ' $b$ ' value ${ }^{x}$ & $50.8 \mathrm{~b}$ & $45.0 \mathrm{a}$ & $45.9 \mathrm{a}$ \\
\hline Flesh browning ${ }^{x}$ & $0.04 \mathrm{a}$ & $0.03 \mathrm{a}$ & $0.40 \mathrm{~b}$ \\
\hline PPO activity $(\mathrm{mL} \mathrm{Abs} / \mathrm{min})^{\mathrm{w}}$ & $156 \mathrm{a}$ & $178 \mathrm{a}$ & $383 \mathrm{~b}$ \\
\hline Resistance to Monilinia fruit $\operatorname{rot}^{\mathrm{v}}$ & $9.5 \mathrm{~b}$ & $5.2 \mathrm{a}$ & $9.39 \mathrm{~b}$ \\
\hline
\end{tabular}

${ }_{\mathrm{z}}$ Mean separation performed within each row by Duncan's multiple range test. $P=0.05$ from a sample size of 50 fruit (unless otherwise indicated) randomly harvested from the 12th leaf of trees thinned to achieve a commercial size of $60 \mathrm{~cm}$ or larger.

${ }^{\mathrm{y}}$ Fruit firmness was measured with a Magness-Taylor firmness tester using an 8-mm tip with the fruit epidermis removed.

${ }^{\mathrm{x}}$ CIELAB $1976 \mathrm{~L} * \mathrm{a} * \mathrm{~b} *$ color space. Flesh browning was measured as the proportion ' $\mathrm{L}$ ' value decrease $12 \mathrm{~h}$ after cutting, as described by Techakanon et al. (2016).

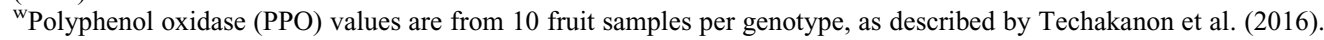

${ }^{\mathrm{v}}$ Disease resistance values are from 20 fruit samples replicated over 3 consecutive years, as described by Gradziel (1994).

\section{Performance}

Trees were evaluated from 2001 to 2016 under standard commercial conditions in the Sacramento and San Joaquin valleys. Trees produced a medium to high crop, larger than that of 'Carson' and comparable to that of 'Andross' and thus needing less thinning following a high-chill winter. 'Kader' bloom was uniform and abundant when chilling hours were above a $700 \mathrm{~h}$ using the Utah model, as occurred at all Central Valley (including Sacramento and San Joaquin Valley) test sites during all years. Bloom time at Central Valley commercial production sites occurred during midseason in relation to other commercial cling peach cultivars, similar to 'Carson' and 'Andross'. 'Kader' fruit were fully clingstone and nonmelting. Fully ripe fruit, as determined by a lack of visible green pigmentation on the fruit epidermis, had an orange-yellow primary ground color with $10 \%$ to $50 \%$ red blush. Fruit skin had a fine, short, and netted pubescence, with no observed tendency to crack. Some split pits occur during low crop years, although at much lower rates than that of either 'Dixon' or 'Andross'. Fruit size and flesh (mesocarp) firmness demonstrated a significant improvement compared to the Carson and Dixon cultivars and were comparable to the Andross cultivar (Table 1). Fruit mass was similar to that of 'Andross' when thinned using recommendations developed for the Andross cultivar (California Canning Peach Association, 2017) to achieve commercial fruit diameters of $60 \mathrm{~mm}$ or larger. 'Kader' fruit were fully acceptable to Califor- nia processors during the 12-year commercial evaluation period. Fruit shape and quality were similar to those of the Andross cultivar (Fig. 3), although with a reduced level of polyphenol oxidase activity and associated flesh browning, but with improved fruit brown rot resistance as caused by Monilinia fructicola (Table 1). Fruit brown rot 3-year average disease severity ratings (measured as the product of the lesion incidence by average lesion diameter $48 \mathrm{~h}$ after controlled inoculation) for 'Kader' were considerably lower than those of cultivar standards Carson and Andross (5.2 vs. 9.5 and 9.4, respectively). The fruit stem cavity of 'Kader' was found to be similar to both the Dixon and Andross cultivars, with a consistently broad and moderately deep cavity necessary for proper alignment of fruit for torque-pitting during processing. Processed flesh color ' $a$ ' and hue values were in the desirable yellow to yellow-gold range (Gradziel, 1994; Tourjee et al., 1998), comparable to the Andross cultivar (Table 1). Unlike 'Dixon' and 'Andross', however, 'Kader' showed a decreased tendency to develop undesirable red anthocyanin staining of the fruit pit cavity and associated pit fragmentation. In addition, fruit tend to maintain good processing quality for up to $10 \mathrm{~d}$ postripening, allowing grower and processor flexibility to provide raw product to the cannery during the critical 'Dixon' gap. Since its release, 'Kader' has become one of the most heavily planted processing clingstone peach cultivars in California, thereby addressing grower and processor needs for a high-quality and good-size peach during the 'Dixon' and 'Andross' maturity seasons.

\section{Availability}

Kader is available as a patented (US Plant Patent 26871) cultivar with licenses granted through the University of California Innovation Services, 1850 Research Park Drive, Suite 100, Davis, CA 95618-6134. Propagation material is distributed as registered virus-tested sources through the Foundation Plant Service of the University of California, 1 Shields Avenue, Davis, CA 95616.

\section{Literature Cited}

California Canning Peach Association. 2017. Cling Peach Almanac. Sacramento, CA.

Gradziel, T.M. 1994. Changes in susceptibility to brown rot with ripening in three clingstone peach genotypes. J. Amer. Soc. Hort. Sci. 119:101-105.

Gasic, K., J.R. Clark, T. Gradziel, D.H. Byrne, C.H. Crisosto, T. Frett, P. Sandefur, T. Hartman, J.F Ramirez, N. Bassil, G. Reighard, C. Peace, and A. Iezzoni. 2011. RosBREED facilitates peach genetic improvement via marker-assisted breeding. HortScience 46:S383-S384.

Gradziel, T.M., W. Beres, and K. Pelletreau. 1993. Inbreeding in California canning clingstone peach cultivars. Fruit Var. J. 47:160-168.

Tourjee, K.R., D.M. Barrett, M.V. Romero, and T.M. Gradziel. 1998. Measuring flesh color variability among processing clingstone peach genotypes differing in carotenoid composition. J. Amer. Soc. Hort. Sci. 123:433-437.

Techakanon, C., T. Gradziel, L. Zhang, and D. Barrett. 2016. Effects of Peach Cultivar on Enzymatic Browning Following Cell Damage from High Pressure Processing. J. Agr. Food Chem., doi: 10.1021/acs.jafc.6b01879. 